\title{
Polymorphism of the Polyketide Synthase Gene phID in Biocontrol Fluorescent Pseudomonads Producing 2,4-Diacetylphloroglucinol and Comparison of PhID with Plant Polyketide Synthases
}

\author{
Alban Ramette, ${ }^{1}$ Yvan Moënne-Loccoz, ${ }^{2}$ and Geneviève Défago ${ }^{1}$ \\ ${ }^{1}$ Phytopathology Group, Institute of Plant Sciences, Swiss Federal Institute of Technology (ETH), $\mathrm{CH}-8092$ \\ Zürich, Switzerland; ' 2 UMR CNRS Ecologie Microbienne, Université Claude Bernard (Lyon 1), F-69622 \\ Villeurbanne cedex, France \\ Accepted 26 January 2001.
}

\begin{abstract}
Many biocontrol fluorescent pseudomonads can protect plants from soilborne fungal pathogens through production of the antifungal secondary metabolite 2,4diacetylphloroglucinol (Phl). One of the phl biosynthetic genes, $p h l D$, encodes a polyketide synthase similar to plant chalcone synthases. Here, restriction analysis of phlD from $39 \mathrm{Phl}^{+}$biocontrol fluorescent pseudomonads yielded seven different banding patterns. The gene was sequenced in seven strains, representing the different restriction patterns. Cluster analysis of phlD restriction data or phlD sequences indicated that phlD polymorphism was high, and two main clusters were obtained when predicted PhlD sequences were compared. When the seven PhlD sequences were studied with those of other procaryotic polyketide synthases (gram-positive bacteria) and plant chalcone synthases, however, $\mathrm{Phl}^{+}$pseudomonads, grampositive bacteria, and plants clustered separately. Yet, sequence analysis of active site regions for PhlD and plant chalcone synthases revealed that $\mathrm{PhID}$ can be considered a member of the chalcone synthase family, which may be interpreted as convergent evolution of key enzymes involved in secondary metabolism. For the $39 \mathrm{Phl}^{+}$pseudomonads, a relationship was found among phlD restriction patterns, phylogenetic groups defined by $16 \mathrm{~S}$ rDNA restriction analysis (confirmed by $16 \mathrm{~S}$ rDNA sequencing), and production levels of $\mathrm{Phl}$ in vitro.
\end{abstract}

Additional keywords: diversity, phylogeny, plant protection.

Certain root-associated fluorescent Pseudomonas spp. capable of protecting plants from soilborne fungal pathogens produce antifungal secondary metabolites (Dowling and O'Gara 1994; Thomashow and Weller 1996). The implication of these bacterial antifungal compounds in disease suppression has been substantiated by comparing wild-type pseudomonads with mutant derivatives in which production of antifungal compound(s) was altered (Keel and Défago 1997). Among antifungal compounds synthesized by pseudomonads,

Corresponding author: G. Défago; Telephone: +41 1632 3869; Fax: +41 1632 1108; E-mail: genevieve.defago@ipw.agrl.ethz.ch 2,4-diacetylphloroglucinol $(\mathrm{Phl})$ is a key secondary metabolite associated with disease suppression in several pathosystems (Fenton et al. 1992; Harrison et al. 1993; Keel et al. 1992). In addition, Phl was found by chemical means in the rhizosphere of plants inoculated with $\mathrm{Phl}^{+}$strains (Bonsall et al. 1997; Keel et al. 1992) or colonized by naturally occurring $\mathrm{Phl}^{+}$ pseudomonads in disease-suppressive soil (Raaijmakers et al. 1999).

Six phl genes are documented in the $\mathrm{Phl}^{+}$strain Pseudomonas fluorescens Q2-87, and one of them, phlD, is essential for the synthesis of the Phl precursor monoacetylphloroglucinol (Bangera and Thomashow 1999). The predicted PhlD protein was identified as a polyketide synthase (PKS) and shares homologies with chalcone synthases (CHSs) and stilbene synthases from plants. Furthermore, amino acid sequence alignments indicate that the putative active site region of PhlD in strain Q2-87 (QLGC $\left.{ }^{138} \mathrm{VAG}\right)$ corresponds well with the unique active site region found in plant $\mathrm{CHS}$ (QQGC $\left.{ }^{169} \mathrm{FAG}\right)$. Bangera and Thomashow (1999) proposed that Phl synthesis was mediated by a novel type of prokaryotic PKS, designated PKS type III. The function of the PhID PKS is to catalyze the condensation of the probable starter molecule acetoacetyl$\mathrm{CoA}$ and the subsequent cyclization step to form the Phl precursor monoacetylphloroglucinol.

In addition, the similarities between PhID and plant CHS raises the possibility of a common evolutionary origin, probably as a result of horizontal gene transfer from plants to the bacteria colonizing them (Bangera and Thomashow 1999; Cook et al. 1995). This hypothesis is in agreement with the facts that i) bacterial transformation can take place inside plant tissues (Bertolla et al. 1999), ii) P. fluorescens can acquire DNA by transformation (Troussieux 2000), and iii) $\mathrm{Phl}^{+}$ pseudomonads can display endophytic behavior (Troxler et al. 1997). For the three other biosynthetic genes of the phlACBD operon, however, homologs were found only in archaebacteria (Bangera and Thomashow 1999). A 4.8-kb DNA fragment carrying $p h l$ biosynthetic genes from Q2-87 hybridized under high-stringency conditions with genomic DNA from other $\mathrm{Phl}^{+}$biocontrol pseudomonads originating from the United States (Oklahoma, Texas, and Washington), Europe (Ireland, Italy, and Switzerland), and Africa (Ghana) (Keel et al. 1996). 
This led these authors to propose that the phl biosynthetic locus is well conserved in $\mathrm{Phl}^{+}$pseudomonads, although more discriminating methods were not used to strengthen this hypothesis.

In contrast, when other strain properties were considered, the collection of $\mathrm{Phl}^{+}$pseudomonads studied by Keel et al. (1996) displayed considerable genotypic and phenotypic diversity. For example, as many as three amplified $16 \mathrm{~S}$ ribosomal DNA restriction analysis (ARDRA) groups and eight randomly amplified polymorphic DNA (RAPD) groups were found among $45 \mathrm{Phl}^{+}$pseudomonads. The diversity of $\mathrm{Phl}^{+}$ pseudomonads has also been characterized for isolates obtained from a single host species in the case of wheat (McSpadden Gardener et al. 2000) and maize (Picard et al. 2000), with a combination of ARDRA, whole-cell BOXpolymerase chain reaction (PCR), enterobacterial repetitive intergenic consensus (ERIC)-PCR, RAPD markers, and/or carbon source utilization profiles. Similarly, large differences exist in the ability of $\mathrm{Phl}^{+}$pseudomonads to produce $\mathrm{Phl}$ under in vitro conditions (Keel et al. 1996). Whether this is linked with strain properties unrelated to the $p h l$ locus and/or features of the $p h l$ locus remains to be assessed.

Our goal was to determine whether or not phlD was polymorphic. In order to carry this out, we used a worldwide collection of $\mathrm{Phl}^{+}$biocontrol fluorescent Pseudomonas spp. In light of the postulated plant origin of phlD in pseudomonads, the gene products deduced from phlD sequences were compared with other members of the type III PKS superfamily from bacteria and plants to establish their evolutionary relationships. In addition, the relationships were assessed among phlD characteristics, $\mathrm{Phl}$ production in vitro, and broad genotypic features of the $\mathrm{Phl}^{+}$pseudomonads because of the importance of these bacteria in biocontrol and Phl-mediated antagonism as a mechanism in plant protection.

\section{RESULTS}

\section{Amplification and restriction analysis of phlD.}

The 745-bp phlD amplicons obtained from $39 \mathrm{Phl}^{+}$biocontrol pseudomonads were analyzed by restriction with HaeIII, $M s p \mathrm{I}, C f o \mathrm{I}, S a u 3 \mathrm{~A}$, or NdeII. The results obtained with these five enzymes were subjected to cluster analysis (Fig. 1). Restriction analysis with HaeIII yielded seven restriction patterns (designated HaeIII-1 to HaeIII-7), and pseudomonads exhibiting a same HaeIII restriction pattern were undistinguishable when analysis was carried out with any of the four other endonucleases (data not shown). The seven clusters were very different from one another (Fig. 1), except for clusters corresponding to HaeIII-3 and HaeIII-4 (79\% similarity) or HaeIII-6 and HaeIII-7 (73\% similarity).

Several HaeIII restriction patterns only comprised pseudomonads from the same geographic location (Table 1), e.g., HaeIII-2 (Quincy, WA, U.S.A.), HaeIII-4 (Morens, Switzerland), or HaeIII-6-HaeIII-7 (Albenga, Italy). Different HaeIII restriction patterns could be observed, however, when all bacteria from Quincy (HaeIII-2 and HaeIII-3), Morens (HaeIII-1, HaeIII-3, and HaeIII-4) or Albenga (HaeIII-1, HaeIII-6, and HaeIII-7) were considered. The nine tobacco isolates (from three different countries) were all within HaeIII-1, but four HaeIII restriction patterns were found with wheat isolates (HaeIII-1, HaeIII-2, HaeIII-3, and
HaeIII-6), and three with tomato isolates (HaeIII-3, HaeIII4, and HaeIII-7).

\section{Analysis of phlD sequences.}

Seven $\mathrm{Phl}^{+}$strains, each displaying a different HaeIII restriction pattern, were chosen to sequence phlD. After phlD sequence alignment, a maximum-likelihood tree was inferred (Fig. 2A). Three main clusters corresponding to CHA0, Q287 , and the five other strains were obtained. Within the latter cluster, three subclusters consisting of F113, (Q65c-80, CM1'A2) and (PITR2, PILH1) were found. Alternative subclusters such as F113 (Q65c-80, CM1'A2) (Fig. 1) and F113, (PITR2, PILH1) were supported by low bootstrap values (34 and $49 \%$, respectively). The same tree topology also was obtained by maximum parsimony or distance-based methods (Neighbor-Joining [NJ] tree, constructed according to the Kimura 2-parameter or the Jukes-Cantor models), except for F113, which was clustered with either Q65c-80 and CM1'A1 or PITR2 and PILH1, although with low bootstrap values of 52 to $66 \%$.

The base composition for phlD is $T=21.5 \%$ ( \pm standard deviation 0.4$), C=26.5 \%( \pm 0.3), A=21.3 \%$ ( \pm 0.6$)$, and $G=$ $30.8 \%$ ( \pm 0.6$)$. No statistical difference was found between the strains, regardless of whether base composition was considered overall or at each of the three codon positions. The rate of nucleotide substitutions in phlD was assessed with the gamma distribution, whose shape is determined by the alpha parameter. The alpha parameter was estimated to be 0.29 on the basis of the topology presented in Figure 2A, the equilibrium frequencies of the four bases, and a transition rate (Ti)transversion rate $(\mathrm{Tv})$ ratio estimated by the same model to be 1.66. A value below 1 for the alpha parameter indicates that the gamma distribution is highly skewed, which means that most sites in phlD have low substitution rates but that substitutional hot spots can exist (Swofford et al. 1996).

Because selection pressure does not have the same effect on the nonsynonymous (leading to amino acid replacement; $d N$ ) and synonymous (silent; dS) rates of nucleotide substitution (Yang 1998), the average $\mathrm{dN}$ and $\mathrm{dS}$ were calculated, with the approximation of the Jukes-Cantor formula. dN (0.100 \pm standard deviation 0.072) was lower statistically (Student $t$ test, with infinite degrees of freedom; $P<0.001)$ than dS $(0.230 \pm$ 0.146 ), and the $\mathrm{dN}-\mathrm{dS}$ ratio was $0.41 \pm 0.09$. Similar results (average $\mathrm{dN}-\mathrm{dS}$ ratio of $0.40 \pm 0.11$ ) were obtained by the Nei and Gojobori (1986) method, implemented with phylogenetic analysis by the maximum-likelihood program (PAML; Z. Yang, University College London, U.K.). This means that bacteria in which mutations of phlD resulted in actual modification of PhlD characteristics were not selected during evolution, i.e., a lack of adaptive protein evolution.

\section{Analysis of predicted PhID sequences.}

A NJ tree was inferred from the predicted PhlD protein sequences (Fig. 2B). Strain CHA0 clustered separately from the six other pseudomonads. Among the latter, four subclusters consisting of Q2-87, (Q65c-80, CM1'A2), F113 and (PITR2, PILH1) were found. The same topology also was obtained when the sequence of bacterial type III PKS (Table 2) was included or a heuristic tree search with maximum parsimony criterion (data not shown) was chosen. The heuristic tree search yielded nine trees, but the 50\%-majority-rule consensus 
tree displayed bootstrap values of only 53 and $73 \%$ for the clusters (CM1'A2, Q65c-80) and (PITR2, PILH1), respectively. Other distance methods, which were calculated on the basis of Poisson correction, the number of differences, or gamma-corrected distances implemented in the molecular evolutionary genetics analysis program (MEGA; S. Kumar, K. Tamura, and M. Nei, Pennsylvania State University, U.S.A.), gave the same topology.

Not surprisingly, the strongest differences in PhID amino acid sequences were obtained between CHAO and the other pseudomonads, with an average of $85.6 \%$ amino acid identity, whereas the other pairwise comparisons gave 96 to $99.6 \%$ identity.

\section{Comparison of PhID with type III PKS \\ from other bacteria and from plants.}

When compared with other type III PKSs such as those from gram-positive bacteria and plants, the seven PhlD proteins clustered separately from the former (Fig. 3). The tree distinguished gram-positive bacteria from plants, with the exception of Nicotiana sylvestris, which appeared in an intermediate position. Amino acid sequence similarity between

\section{$\%$ similarity of $p h I D$}

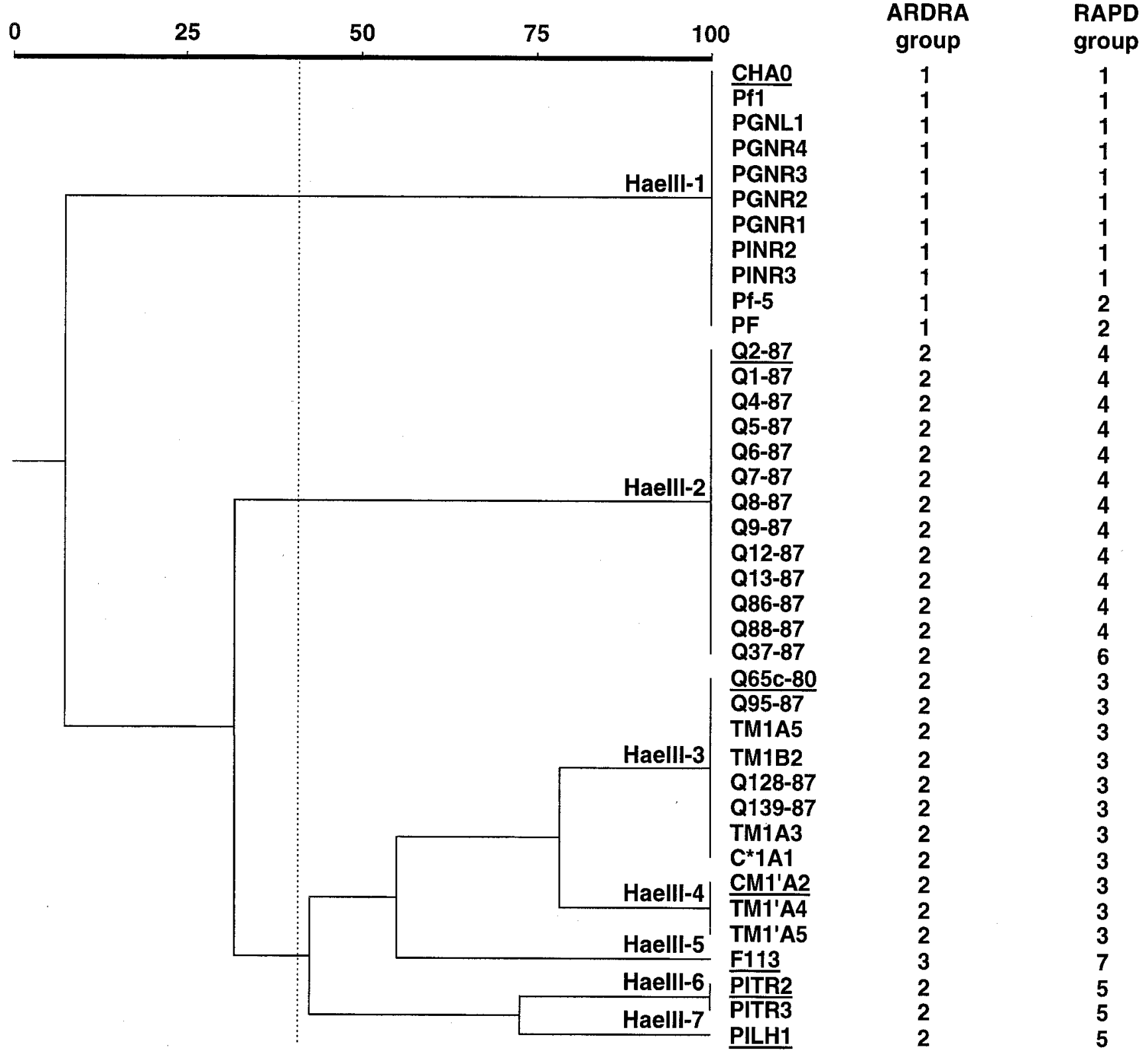

Fig. 1. Comparison of phlD restriction patterns (unweighed pair group method with averages [UPGMA] tree with Jaccard's pairwise similarity coefficient) for $39 \mathrm{Phl}^{+}$biocontrol fluorescent pseudomonads and relationships with broad genotypic properties (ARDRA and RAPD groups) (Keel et al. 1996) of the strains. Polymerase chain reaction-restriction fragment length polymorphism analysis of $p h l D$ was carried out with five enzymes, although one of them (HaeIII) was enough to yield the seven phlD restriction groups (termed HaeIII-1-HaeIII-7). The seven strains for which phlD was subsequently sequenced are underlined. The dotted line corresponds to a $40 \%$ similarity level. 
PhlD (on the basis of the seven deduced sequences) and other bacterial type III PKS was 42 to $64 \%$ (identity from 25 to $49 \%$ ). The highest values obtained were with Streptomyces griseus (Table 2). Similarity between PhlD and plant type III PKS was 43 to $50 \%$ (identity was 22 to $31 \%$ ), when CHA0, Q2-87, or F113 were considered.

The functional role of key amino acid residues is documented for certain plant type III PKSs (Lanz et al. 1991). Some of these residues also were found in PhlD proteins and other bacterial type III PKSs (Fig. 4) such as plant $\mathrm{C}^{169}$, a cysteine residue that is essentially responsible for the catalytic activity of plant CHSs. In addition to this active cysteine, the conservation of a serine subunit contact site ( $S^{158}$ in plants) and a glutamine residue ( $\mathrm{Q}^{166}$ in plants) could lead to a similar catalytic pocket in PhlD proteins and most plant type III PKSs. Nevertheless, cysteines in positions 135 and 195 (both implicated in substrate specificity) and lysine $\mathrm{K}^{180}$ (important for enzymatic structure and function) in plant type III PKSs were not present in bacterial counterparts. Threonine, serine, and asparagine, respectively, were found in place of these amino acids in PhlD sequences. Noticeably, lysine and asparagine codons differ only at the third nucleotide position (purine and pyrimidine, respectively) and, after a single transversion, there is enough to yield an asparagine instead of a lysine.

Kyte-Doolittle hydropathy plots derived from predicted PhlD sequences were very similar from one to the other, yet CHA0 could be differentiated from other $\mathrm{Phl}^{+}$pseudomonads such as Q2-87 (Fig. 5A) or F113 (Fig. 5B), especially when its hydrophobic peak in position 240 was considered. The similarity between PhID proteins and PKSs from gram-positive bacteria or plants was less pronounced, as illustrated when comparing CHA0 with $S$. griseus (Fig. 5C) or Lycopersicon esculentum (Fig. 5D).

\section{Relationship between $p h l D$ polymorphism} and broad genotypic features for $39 \mathrm{Phl}^{+}$pseudomonads.

Among the $39 \mathrm{Phl}^{+}$biocontrol fluorescent pseudomonads, a good relationship was found between groups defined by phlD PCR-restriction fragment length polymorphism (RFLP) and those defined by broad genotypic features (ARDRA or RAPD fingerprints) (Fig. 1). Indeed, HaeIII-1 corresponded to group ARDRA1, HaeIII-5 to ARDRA3, and the five other phlD restriction patterns were all found in ARDRA2 strains (Fig. 1). Additional subdivisions were made within ARDRA2 by comparing RAPD groups. HaeIII-2 was found in RAPD groups 4 and 6, HaeIII-3 and HaeIII-4 in RAPD group 3, and HaeIII-6 and HaeIII-7 in RAPD group 5.

The 16S rRNA genes of reference strains CHA0 (group ARDRA1), Q2-87 (ARDRA2), and F113 (ARDRA3) were sequenced. Sequence identity was $97.6 \%$ between CHA0 and Q2-87 (1,530 nucleotides overlap), 97.8\% between CHA0 and F113 (1,529 nucleotides overlap), and 99.5\% between Q2-87 and F113 (1,527 nucleotides overlap). The three sequences were aligned with other Pseudomonas spp. 16S rRNA sequences (Ribosomal Database Project database), and a NJ tree was inferred with Pseudomonas putida IAM1236 as the out group (Fig. 6). Noticeably, CHA0 clearly clustered away from Q2-87 and F113 because it was found in the cluster containing Pseudomonas syringae, Pseudomonas caricapapayae, and Pseudomonas chlororaphis. Strains Q2-87 and F113 clustered close to $P$. corrugata ATCC29736 (sequence identity was

Table 1. Origin and biocontrol properties of $\mathrm{Phl}^{+}$fluorescent Pseudomonas spp. strains used in the study

\begin{tabular}{|c|c|c|c|}
\hline Strain & Biocontrol activity $^{\mathrm{a}}$ & Source $^{b}$ & Reference \\
\hline \multicolumn{4}{|l|}{ Reference strains } \\
\hline CHA0 & Tobacco $(\mathrm{Tb})$, wheat $(\mathrm{Ggt})$, cucumber $(\mathrm{Pu})$ & Tobacco; Morens, Switzerland & Stutz et al. 1986 \\
\hline Q2-87 & Wheat (Ggt) & Wheat; Quincy, WA, U.S.A. & Vincent et al. 1991 \\
\hline Q65c-80 & Wheat (Ggt) & Wheat; Quincy, WA, U.S.A. & Harrison et al. 1993 \\
\hline Pf-5 & Cotton (Pu, Rs), Cucumber (Pu) & Cotton; Texas, U.S.A. & Howell and Stipanovic 19 \\
\hline F113 & Sugar beet $(\mathrm{Pu})$ & Sugar beet; Ireland & Fenton et al. 1992 \\
\hline $\mathrm{PF}$ & Wheat (St) & Wheat; Oklahoma, U.S.A. & Levy et al. 1992 \\
\hline \multicolumn{4}{|l|}{ Isolates from Quincy, WA, U.S.A. } \\
\hline $\begin{array}{l}\text { Q1-87, Q4-87, Q5-87, Q6-87, Q7-87, } \\
\text { Q8-87, Q9-87, Q12-87, Q13-87, } \\
\text { Q37-87, Q86-87, Q95-87, } \\
\text { Q139-87 }\end{array}$ & Wheat (Ggt) & Wheat & Keel et al. 1996 \\
\hline Q88-87, Q128-87 & Wheat (Ggt) & Wheat & Harrison et al. 1993 \\
\hline \multicolumn{4}{|l|}{ Isolates from Morens, Switzerland } \\
\hline Pf1 & Tobacco $(\mathrm{Tb})$, cucumber $(\mathrm{Pu})$ & Tobacco & Keel et al. 1996 \\
\hline 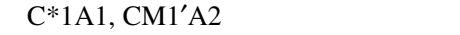 & Cucumber (Pu, Ps), cotton (Rs) & Cucumber & Fuchs and Défago 1991 \\
\hline TM1A3, TM1A5, TM1B2 & Cucumber (Pu, Ps), cotton (Rs) & Tomato & Fuchs and Défago 1991 \\
\hline TM1'A4, TM1'A5 & Cucumber (Pu, Ps), cotton (Rs) & Tomato & Keel et al. 1996 \\
\hline \multicolumn{4}{|l|}{ Isolates from Albenga, Italy } \\
\hline PINR2, PINR3 & Cucumber $(\mathrm{Pu})$, tomato (Forl) & Tobacco & Keel et al. 1996 \\
\hline PITR2, PITR3 & Cucumber $(\mathrm{Pu})$, tomato (Forl) & Wheat & Keel et al. 1996 \\
\hline PILH1 & Cucumber (Pu), tomato (Forl) & Tomato & Keel et al. 1996 \\
\hline \multicolumn{4}{|l|}{ Isolates from IITA soil (Ghana) } \\
\hline $\begin{array}{l}\text { PGNR1, PGNR2, PGNR3, PGNR4, } \\
\text { PGNL1 }\end{array}$ & Cucumber $(\mathrm{Pu})$, tomato (Forl) & Tobacco & Keel et al. 1996 \\
\hline
\end{tabular}

${ }^{\mathrm{a}} \mathrm{Tb}$, Thielaviopsis basicola; Ggt, Gaeumannomyces graminis var. tritici; Pu, Pythium ultimum; Rs, Rhizoctonia solani; Ps, Phomopsis sclerotioides; St, Septoria tritici; Forl, Fusarium oxysporum f. sp. radicis-lycopersici.

${ }^{\mathrm{b}}$ Pseudomonas spp. strains were isolated from roots, with the exception of strain PF, which was isolated from wheat leaves. Root samples consisted of macerated roots or roots previously washed of soil. 
99.3\% for Q2-87 and 99.6\% for F113, compared with $97.5 \%$ for CHA0) but were not distantly separated from the two $P$. fluorescens strains included in the tree. Comparison of $\mathrm{Phl}^{+}$ pseudomonads with $P$. fluorescens DSM50090 and IAM12022 (98.2\% sequence identity between the two) yielded 97.5 and 98.2\% sequence identity, respectively, for Q2-87; 97.7 and $98.2 \%$, respectively, for F113; and only 96.2 and $96.6 \%$, respectively, for CHA0.

\section{Relationship between phlD polymorphism and production of Phl in vitro.}

The relationship between phlD PCR-RFLP groups and Phl production was assessed on malt agar (Keel et al. 1992) and King's B agar (King et al. 1954) (Fig. 7A and B). Raw data of $\mathrm{Phl}$ production were obtained by Keel et al. (1996). Because several phlD PCR-RFLP groups comprise only a few bacteria each, the statistical significance of the relationship investigated for phlD clusters, which were defined at an arbitrarily chosen similarity level of $40 \%$ (Fig. 1) and were congruent with clusters derived from phlD sequence data (Fig. 2A). Thus, Phl production for HaeIII-1 $(n=11)$, HaeIII-2 $(n=13)$, and the cluster gathering HaeIII-3 to HaeIII-7 $(n=15)$ was 3.8 ( \pm standard deviation of 2.3), $18.1( \pm 8.5)$ and $27.8( \pm 12.1)$ $\mu \mathrm{g}$, respectively, per $\mathrm{ml}$ of malt agar and $1.2( \pm 3.9), 14.3( \pm$ $8.6)$, and $30.7( \pm 14.0) \mu \mathrm{g}$, respectively, per $\mathrm{ml}$ of King's B agar. Each of the three groups was statistically different from the others $(P<0.05)$, regardless of the growth medium considered.

\section{DISCUSSION}

phlD is polymorphic.

Hybridization experiments carried out under highstringency conditions suggest that the phl biosynthetic locus was well conserved among $\mathrm{Phl}^{+}$biocontrol fluorescent pseudomonads (Keel et al. 1996). Here, however, PCR-RFLP analysis revealed that one of the structural genes involved in Phl production, phlD, displayed substantial polymorphism as i) several different restriction patterns were obtained and ii) similarity levels between clusters were low (Fig. 1). phlD PCR-RFLP patterns agreed with those predicted by virtual restriction analysis of phlD sequences. Furthermore, the tree topology obtained for $p h l D$ with restriction data was congruent with that derived from $p h l D$ sequences, indicating that restriction analysis could represent a valuable tool in ecological studies of $\mathrm{Phl}^{+}$Pseudomonas spp. populations. In the current work, certain phlD PCR-RFLP patterns appeared to be associated with particular soils or plant hosts, whereas others were not. Sampling biases were probably important, however, and thus the relationship between the phlD PCR-RFLP pattern and soil or plant host will have to be assessed with a larger collection of $\mathrm{Phl}^{+}$pseudomonads. Indeed, other $\mathrm{Phl}^{+}$fluorescent pseudomonads have been isolated from plants, especially monocots (McSpadden Gardener et al. 2000; Picard et al. 2000).

\section{phlD characteristics suggest absence of positive selection on PhID.}

Despite the fact that phlD displayed significant polymorphism, the analysis of synonymous and nonsynonymous substitutions and the estimated value of the alpha parameter of the gamma distribution suggests a lack of adaptively driven amino acid substitutions in PhlD (absence of positive selection). Indeed, many synonymous substitutions, i.e., not leading to amino acid replacement, were observed. The $\mathrm{dN}-\mathrm{dS}$ ratio was well below 1 , which means that advantageous nonsynonymous mutations were much less frequent than synony-
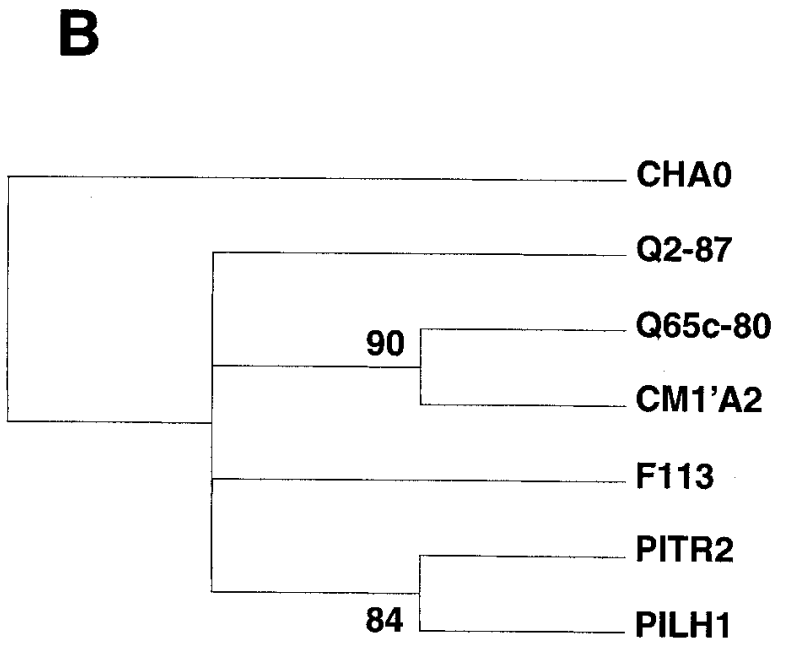

\subsection{2}

Fig. 2. Phylogenetic relationships on the basis of $\mathbf{A}$, phlD nucleotide and $\mathbf{B}$, predicted PhlD amino acid sequences between Phl ${ }^{+}$biocontrol fluorescent pseudomonads representing the seven phlD polymerase chain reaction-restriction fragment length polymorphism groups (HaeIII-1-HaeIII-7) (Fig. 1). Strains studied include CHA0 (group HaeIII-1), Q2-87 (HaeIII-2), Q65c-80 (HaeIII-3), CM1'A2 (HaeIII-4), F113 (HaeIII-5), PITR2 (HaeIII-6), and PILH1 (HaeIII-7). A, The phlD tree (depicted as midpoint rooted) was constructed by maximum likelihood (DNAML) and the robustness of the inferred tree was assessed by 100 bootstrap replicates. Nodal support is indicated when higher than 50\%. Scale bar indicates the number of nucleotide substitutions per site. B, The PhlD tree (strict consensus tree; 1,000 bootstrap replicates) was constructed by the Neighbor-Joining method, with the Kimura formula. 
mous (silent) mutations. In the absence of positive selection, most nonsynonymous substitutions in proteins are deleterious and result in purifying selection (Kimura 1983; Miyata and Yasugana 1980; Nielsen and Yang 1998), which apparently was the case for PhlD. A direct consequence of the relative importance of synonymous substitutions is that fewer clusters were obtained for PhlD than for phlD (Fig. 2). The relationship observed between strains when considering phlD sequences, however, also was found, to a large extent, in the PhlD tree. In both clusters, CHA0 clearly was different from the six other pseudomonads, whereas Q65c-80 clustered with CM1'A2 and PITR2 with PILH1.

The lack of positive selection for PhlD agrees with an alpha parameter lower than 1 , which indicates that most sites in the sequence have low substitution rates or are almost invariable. In fact, as many as 523 of the 746 nucleotides $(70.1 \%)$ in phlD were constant, whereas 152 were parsimony uninformative and 71 parsimony informative.

\section{PhID differs from type III PKSs found in gram-positive bacteria and plants.}

CHSs (EC 2.3.1.74) are plant members of the type III PKS superfamily (Bangera and Thomashow 1999) and implicated in the biosynthesis of flavonoids (Martin 1993; Schröder and Schröder 1990; Tropf et al. 1995). Although CHS-type reactions also can be catalyzed by enzymes of other plant secondary metabolism pathways such as valerophenone synthase (Zuurbier et al. 1998), CHSs display little similarity to other eukaryotic-condensing enzymes and, therefore, represent an independent development (Tropf et al. 1995). In this work, PhlD (predicted from phlD sequences) and plant CHS displayed common features, as indicated by the comparison of amino acid sequences (Table 2 and Fig. 4) and Kyte-Doolittle hydropathy plots (Fig. 5D). Cluster analysis clearly distin- guished between PhID and plant CHS (Fig. 3), however, and comparison of the active site region indicated differences that are likely to influence their substrate specificity (Fig. 4).

Type III PKSs also are known in other microorganisms, all of which correspond to gram-positive bacteria (Funa et al. 1999; Sorokin et al. 1996; Ueda et al. 1995). In S. griseus, production of a red-brown pigment associated with the PKS RppA (Ueda et al. 1995) was lost after site-directed mutagenesis of rppA targeting the central cysteine residue (Funa et al. 1999). This indicates that the cysteine had the same catalytic function as in plant CHSs, where it binds to the substrate (Lanz et al. 1991). Interestingly, type III PKSs from gram-positive bacteria were found between PhlD and plant type III PKS following cluster analysis (Fig. 3). The PKS closest to PhlD was from $S$. griseus, based on cluster analysis (Fig. 3) and an amino acid sequence comparison (Table 2). In cluster analysis, S. griseus was found at a distance of approximately 0.3 amino acid substitutions per site from other gram-positive bacteria. In addition, one of the plants (Nicotiana sylvestris) was found between the other plants and gram-positive bacteria. Therefore, it is possible that type III PKSs from fluorescent pseudomonads, grampositive bacteria, and higher plants arose independently in each of the three phyla and may represent a case of convergent evolution of key enzymes involved in the biosynthesis of secondary metabolites such as pigments, flavonoids, and antimicrobial compounds rather than the result of horizontal gene transfer events between those phyla, as speculated earlier based on a smaller number of available sequences (Bangera and Thomashow 1999; Cook et al. 1995). This is in accordance with the observation that, at the scale of the $39 \mathrm{Phl}^{+}$pseudomonads studied in our report, each phlD PCR-RFLP pattern was associated strongly with particular ARDRA and RAPD groups (Fig. 1).

Table 2. Comparison of PhlD from Pseudomonas strain CHA0 with type III PKSs from Gram-positive bacteria and plants, based on the percentages of amino acid sequence identity and similarity. Gram-positive and plant sequences were first aligned with PhID and then subjected to the calculations (the sequence from CHA0 was introduced first in the program BLAST 2 sequences)

\begin{tabular}{|c|c|c|c|}
\hline \multirow[b]{2}{*}{ Organism } & \multirow[b]{2}{*}{ Accession number ${ }^{b}$} & \multicolumn{2}{|c|}{ CHA0 $^{\mathbf{a}}$} \\
\hline & & Identity $^{c}$ & Similarity \\
\hline \multicolumn{4}{|l|}{ Gram-positive bacteria } \\
\hline Streptomyces griseus ${ }^{\mathrm{d}}$ & BAA33495 & $45 \%(249)$ & $59 \%$ \\
\hline Bacillus subtilis & P54157 & $26 \%(225)$ & $46 \%$ \\
\hline Deinococcus radiodurans & A75315 (strain R1) & $28 \%(233)$ & $42 \%$ \\
\hline Mycobacterium tuberculosis (1) & C70985 (pks11) & $28 \%(233)$ & $44 \%$ \\
\hline Mycobacterium tuberculosis (2) & G70621 (pks10) & $30 \%(240)$ & $45 \%$ \\
\hline \multicolumn{4}{|l|}{ Plants } \\
\hline Gerbera hybrida (1) & CAA62683.1 & $28 \%(238)$ & $45 \%$ \\
\hline Gerbera hybrida (2) & P48391 & $26 \%(241)$ & $43 \%$ \\
\hline Vitis vinifera $(1)$ & P51090 & $28 \%(236)$ & $45 \%$ \\
\hline Vitis vinifera (2) & BAA31259 & $28 \%(236)$ & $45 \%$ \\
\hline Hordeum vulgare & Q96562 & $27 \%(236)$ & $43 \%$ \\
\hline Solanum tuberosum & Q43188 & $28 \%(236)$ & $44 \%$ \\
\hline Petunia hybrida & P22928 & $27 \%(236)$ & $45 \%$ \\
\hline Lycopersicon esculentum & S12224 & $28 \%(226)$ & $45 \%$ \\
\hline Nicotiana sylvestris & T15054 (anther) & $22 \%(235)$ & $44 \%$ \\
\hline
\end{tabular}

${ }^{a}$ Percentages of identity (and similarity) differed by $5 \%$ units or less when gram-positive and plant polyketide synthases (PKS) were compared with any of the other six $\mathrm{Phl}^{+}$pseudomonads sequenced (rather than CHA0).

${ }^{b}$ A GenBank data search was carried out via the ENTREZ service from the National Center for Biotechnology Information (Bethesda, MD, U.S.A.). Details in parentheses were used.

${ }^{c}$ Number of amino acids considered in the calculations is given in parentheses.

${ }^{\mathrm{d}}$ Highest values were obtained with $\mathrm{S}$. griseus. PKS identity between the six other Phl ${ }^{+}$pseudomonads and S. griseus ranged from 45 to $49 \%$ (59 to $64 \%$ similarity). 
Phylogenetic diversity of $\mathrm{Phl}^{+}$pseudomonads.

The $39 \mathrm{Phl}^{+}$pseudomonads studied here have been characterized genetically with ARDRA (Keel et al. 1996), and three phylogenetic groups were identified. ARDRA patterns were in agreement with those (Fig. 6) obtained by virtual restriction analysis of the $16 \mathrm{~S}$ rRNA sequences of CHA0, Q2-87, and F113. ARDRA groups 1, 2, and 3, defined by Keel et al. (1996), corresponded to ARDRA groups A, B, and C in the phlD ${ }^{+}$fluorescent pseudomonad study by McSpadden Gardener et al. (2000). AluI was not discriminative in the two investigations, but Picard et al. (2000) found as many as four ARDRA profiles with this enzyme when comparing 167 phlD ${ }^{+}$fluorescent pseudomonads from soil and maize roots. In the latter work, $\mathrm{Phl}^{+}$strains also producing pyoluteorin, which are only known in ARDRA1 (Keel et al. 1996) and phlD group HaeIII-1 (Fig. 1), were not found. Here, the comparison of 16S rRNA sequences from strains CHA0 (ARDRA1), Q2-
87 (ARDRA2), and F113 (ARDRA3) indicate that ARDRA3 is closer to ARDRA2 than to ARDRA1 (Fig. 6) and confirms previous results of ARDRA clustering (Keel et al. 1996) as well as subsequent findings (McSpadden Gardener et al. 2000).

Strains CHA0 (Stutz 1985; Stutz et al. 1986), Q2-87 (Pierson and Weller 1994), and F113 (Shanahan et al. 1992) were originally classified as P. fluorescens, largely on the basis of phenotypic tests. When considering $16 \mathrm{~S}$ rRNA sequences, the three strains would belong to the "P. fluorescens lineage," which gathers $P$. fluorescens, Pseudomonas aureofaciens, $P$. chlororaphis, Pseudomonas marginalis, Pseudomonas tolaasi, and Pseudomonas viridiflava, proposed by Moore et al. (1996). The 16S rRNA sequences of Q2-87 and F113 are compatible with the $P$. fluorescens species, based on criterion (a threshold homology level of $\leq 97 \%$ ) determined by Stackebrandt and Goebel (1994), whereas CHA0 is not (only 96.2 and $96.6 \%$ homology with P. fluorescens DSM50090 and

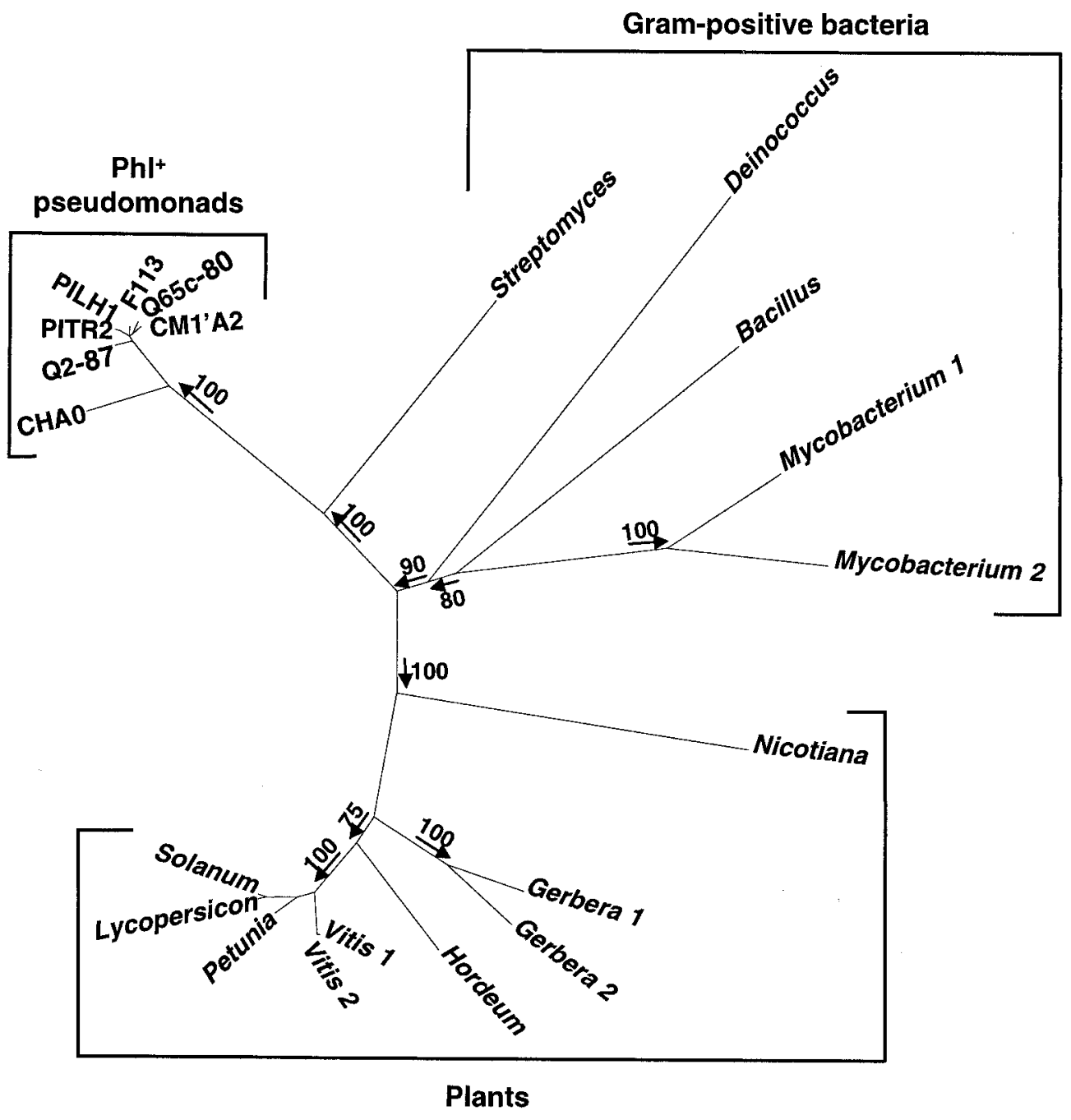

0.1

Fig. 3. Relationships between predicted amino acid sequences of PhlD from $\mathrm{Phl}^{+}$biocontrol fluorescent pseudomonads and type III polyketide synthase from gram-positive bacteria and plants. The distance tree was generated by the Neighbor-Joining method implemented in PAUP. Nodal robustness was assessed by 100 bootstrap replicates. The 50\%-majority-rule consensus tree is represented. Bootstrap values within the Pseudomonas spp. and plant clusters are not shown. Arrows indicate the nodes to which bootstrap values must be attributed. Scale bar represents the number of amino acid substitutions per site. Only genus names are given (Table 2 includes full names and accession numbers). 
IAM12022, respectively). This raises the possibility that strain CHA0 should be considered to belong to a different species compared with Q2-87 and F113, in accordance with the observation that $\mathrm{CHA} 0$ clustered next to the $P$. syringae group (Fig. 6), as defined in Anzai et al. (2000). It should be remembered, however, that the current taxonomy of the genus Pseudomonas sensu stricto remains very unsatisfactory because of the large genomic diversity found within most Pseudomonas species described so far (Bossis et al. 2000). P. fluorescens, for instance, is expected to be subdivided into several different species once it is fully reassessed by DNA-DNA hybridization studies (Bossis et al. 2000; Palleroni 1992). In this context, it could be that the subdivisions made within ARDRA groups on the basis of RAPD clustering (Fig. 1) or spacer ARDRA (Sharifi-Tehrani et al. 1998) are more relevant than ARDRA groups in phylogenetic terms.

Patterns of Phl production linked with $p h l D$ polymorphism and phylogenetic diversity.

Individual $\mathrm{Phl}^{+}$pseudomonads differ in their ability to produce $\mathrm{Phl}$ in vitro (Keel et al. 1996). Some of these differences could be explained by distinguishing $\mathrm{Phl}^{+}$strains capable of producing pyoluteorin (group ARDRA1) from ARDRA2 strains (Sharifi-Tehrani et al. 1998). We followed this approach further by grouping $\mathrm{Phl}^{+}$pseudomonads according to their phlD restriction profile (Fig. 7), which resulted in additional subdivisions compared with the mere distinction between groups ARDRA1 and ARDRA2. Indeed, statistical differences were found when comparing the phlD clusters HaeIII-1, HaeIII-2, and HaeIII-3 to HaeIII-7 (defined at $40 \%$ similarity), which enabled us to discriminate strains within group ARDRA2. Unfortunately, only a small number of strains exhibiting phlD restriction patterns HaeIII-4, HaeIII-5, HaeIII-6, or HaeIII-7 have been identified so far, but this number is likely to increase with phlD restriction analysis of other $\mathrm{Phl}^{+}$pseudomonads, which will allow a comparison to be made at the restriction pattern level rather than with broad phlD clusters. Nevertheless, phlD restriction patterns may be useful as markers in ecological studies or when selecting $\mathrm{Phl}^{+}$ pseudomonads for specific biocontrol applications.

Whether phlD polymorphism is of any relevance in terms of $\mathrm{Phl}$ production is unknown. Indeed, these differences in $\mathrm{Phl}$

\begin{tabular}{|c|c|c|c|c|c|c|c|c|c|c|c|c|c|}
\hline & & (1) & & (2) & & (3) & & (4) & & (5) & & (6) & \\
\hline Lycopersicon & VVF & $\mathbf{C}$ & TTS ... RP & $\mathbf{s}$ & VK...Y & $\mathbf{Q}$ & $\mathbf{Q}$ & GC & FAG . . IA & $\mathbf{K}$ & DLA...VV & C & SEITAVTF \\
\hline Solanum & VVF & C & TTS ...RP & $\mathbf{S}$ & VK...Y & $Q$ & $\mathbf{Q}$ & GC & FAG . . ILA & $\mathbf{k}$ & DLA...VV & C & SEITAVTF \\
\hline Petunia & IVF & C & TTS . . RS & $\mathbf{S}$ & VK...Y & $Q$ & $\mathbf{Q}$ & $\mathbf{G C}$ & FAG . . . LA & $\mathbf{K}$ & DLA...VV & c & SEITAVTF \\
\hline Vitis 1 & LVF & $\mathbf{C}$ & TTS ...KP & $\mathbf{s}$ & VK...Y & $\mathbf{Q}$ & $\mathbf{Q}$ & $\mathbf{G C}$ & FAG ... LA & $\mathbf{K}$ & DLA...VV & C & SEITAVTF \\
\hline vitis 2 & LVF & $\mathbf{c}$ & TTS...KP & $\mathbf{s}$ & $\mathbf{V K} \ldots \mathbf{Y}$ & Q & $\mathbf{Q}$ & $G C$ & FAG . . LA & $\mathbf{K}$ & DLA...VV & $\mathbf{c}$ & SEITAVTF \\
\hline Gerbera 1 & LIF & C & TTA...SP & $\mathbf{s}$ & IS... Y & $\mathbf{Q}$ & $\mathbf{Q}$ & GC & SAG ... IA & $\mathbf{K}$ & DLA... VV & c & CEITAIIF \\
\hline Gerbera 2 & IIF & $\mathbf{c}$ & TTA...SP & $\mathbf{s}$ & VK...Y & $Q$ & $\mathbf{Q}$ & $\mathrm{GC}$ & AAG . . LA & $\mathbf{K}$ & DLA... IV & c & SEITAILF \\
\hline Hordeum & LVF & C & TTS ...SP & $\mathbf{T}$ & VK...Y & $\mathbf{Q}$ & $Q$ & GC & FGG. . . LA & $\mathbf{K}$ & DIA...VV & c] & SEITAMAF \\
\hline Nicotiana & IVI & $\mathbf{v}$ & SSS. & $\mathbf{D}$ & IG...Y & $\mathbf{F}$ & $\mathbf{L}$ & GC & YGG...VA & $\mathbf{K}$ & DIA. . . LT & $T$ & SETTILGF \\
\hline & & & & & & & & & & & & & \\
\hline Mycobacterium 1 & IAT & $\mathbf{A}$ & TVT ...RP & $\mathbf{D}$ & VR...F & $\mathbf{G}$ & $\mathbf{L}$ & GC & VAG...RL & $\mathbf{R}$ & DYL ...IV & $\mathbf{S}$ & VELCESLTY \\
\hline MYcobacterium 2 & LIT & $\mathbf{A}$ & TVT...RA & $\mathbf{D}$ & VR ..F & G & $\mathbf{L}$ & GC & VAG...RI & $\mathbf{H}$ & DYL ...LV & $\mathbf{s}$ & VELCESLTY \\
\hline streptomyces & IVY & $\mathbf{v}$ & SCT ...RP & $\mathbf{E}$ & TR...A & $\mathbf{Q}$ & $\mathbf{I}$ & $G C$ & AAG . . RA & $\mathbf{H}$ & DFC...IV & $\mathbf{S}$ & CEFCESCI \\
\hline Deinococcus & vVv & $\mathbf{v}$ & NTS. . . NP & $\mathbf{H}$ & AA...W & $\mathbf{G}$ & $\mathbf{L}$ & GC & AGG...RA & A & DLV...YV & $\mathbf{A}$ & VELCESLTI \\
\hline Bacillus & VFF & $\mathbf{v}$ & SST ...SP & $\mathbf{Y}$ & TK...W & $\mathbf{G}$ & $\mathbf{L}$ & GC & AGG ...RA & A & EYC...VI & $\mathbf{S}$ & AELCESLTF \\
\hline $\mathrm{hl}^{*} \mathrm{p}$ & & & & & & & & & & & & & \\
\hline CHAO & VIV & $\mathbf{T}$ & SCT ...PT & $\mathbf{s}$ & TV...A & $\mathbf{Q}$ & $\mathbf{L}$ & GC & VAG . . RA & $\mathbf{N}$ & DFA...IV & $\mathbf{S}$ & LEFSSLC \\
\hline Q2-87 & VAV & $\mathbf{T}$ & SCT ...RT & $s$ & TV....A & $\mathbf{Q}$ & $I$ & $G C$ & VAG. . . RA & $\mathbf{N}$ & DFA...IV & $\mathbf{S}$ & LEFSSLĆY \\
\hline $265 c-80$ & VAV & $\mathbf{T}$ & SCT . . RT & $\mathbf{s}$ & TV...A & $\mathbf{Q}$ & $\mathbf{L}$ & $G C$ & AAD . . RA & $\mathbf{N}$ & DFA...IV & $\mathbf{s}$ & LEFSSLCE \\
\hline $\mathrm{CM} 1$ 'A2 & VAV & $\mathbf{T}$ & SCT . . RA & $\mathbf{s}$ & TV ...A & $\mathbf{Q}$ & L & GC & VAG . . RA & $\mathbf{N}$ & DFA...IV & $\mathbf{S}$ & LEFSSLCC \\
\hline F113 & VAV & $\mathbf{T}$ & SCT ...RT & $\mathbf{s}$ & TV ...A & $Q$ & L & GC & VAG...RA & $\mathbf{N}$ & DFA...IV & $\mathbf{S}$ & LEFSSLCு \\
\hline PITR2 & VAV & $\mathbf{T}$ & SCT . . RT & $\mathbf{s}$ & TV...A & $\mathbf{Q}$ & L & $G C$ & VAG ...RA & $\mathbf{N}$ & DFA. . IV & $\mathbf{s}$ & LEFSSICE \\
\hline PILH1 & VAV & $\mathbf{T}$ & SCT ...RT & $\mathbf{s}$ & TV...A & 2 & $\mathrm{~L}$ & GC & VAG . . . & $N$ & DFA...IV & $\mathbf{s}$ & LEFSSLC \\
\hline
\end{tabular}

Fig. 4. Alignment of predicted amino acid sequences for the putative active site region of $\mathrm{PhlD}$ from $\mathrm{Phl}^{+}$biocontrol fluorescent pseudomonads and type III polyketide synthase (PKS) from other bacteria and the active site region from plant chalcone synthases (CHS; Table 2). Conserved residues of particular interest in plant CHS are indicated by boxes. (1) Cysteine $\left(\mathrm{C}^{135}\right)$ from plant CHS implicated in substrate specificity and corresponding to threonine $\left(T^{104}\right)$ in PhlD. (2) Serine $\left(S^{158}\right)$ subunit contact site corresponding to $S^{127}$ in PhlD. (3) Glutamine $\left(Q^{166}\right)$ residue conserved in most plant CHSs and corresponding to $\mathrm{Q}^{166}$ in the PKS of Streptomyces griseus and $\mathrm{Q}^{135}$ in PhlD proteins. (4) The glycine cysteine (GC) box corresponds to the conserved region with its putative (formally established for S. griseus and all plants, except Nicotiana sylvestris) catalytic cysteine residue ( $\mathrm{C}^{138}$ for Q2-87 and $\mathrm{C}^{169}$ for the other bacteria and plants). (5) Lysine $\left(\mathrm{K}^{180}\right)$ residue, which corresponds to asparagine $\left(\mathrm{N}^{149}\right)$ in PhlD, conserved strictly in plant. (6) $\mathrm{C}^{195}$ involved in product specificity in plant CHS. $\mathrm{C}^{171}$ for PhlD proteins and $\mathrm{C}^{199}$ for other bacterial PKSs are underlined to indicate potential binding sites for the substrate. 
production may be explained by the link between phlD characteristics and other strain properties, as illustrated by ARDRA and RAPD groups (Fig. 1). Furthermore, whether data obtained in vitro with the use of two laboratory media is of any relevance when considering actual $\mathrm{Phl}$ production in situ, i.e., in the rhizosphere, remains to be established. In this work, no clear relationship was found between $\mathrm{Phl}$ production in vitro for a given phlD restriction group and the origin (plant host or geographic location) of the strains, but perhaps $\mathrm{Phl}^{+}$ biocontrol strains from a given $p h l D$ restriction group are par- ticularly suited for production of $\mathrm{Phl}$ when colonizing a specific host plant or in a given soil type. This issue deserves further attention because of its potential implications in terms of microbial ecology and plant protection.

\section{MATERIALS AND METHODS}

Organisms, culture conditions, and storage.

$\mathrm{Phl}^{+}$fluorescent Pseudomonas spp. strains used in this study are listed in Table 1 . All strains hybridized to a $4.8-\mathrm{kb}$ DNA probe harboring the phl biosynthetic genes from strain
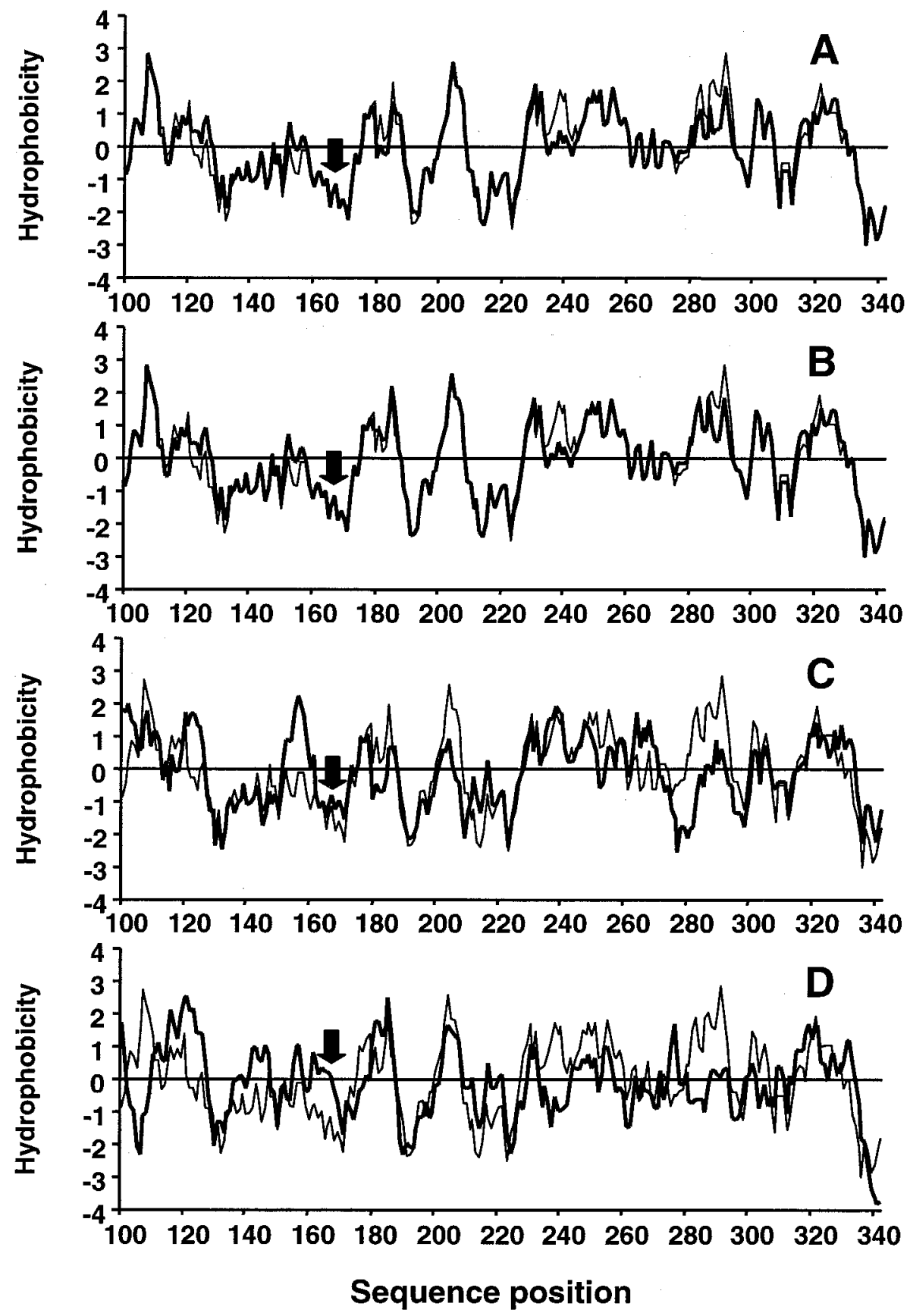

Fig. 5. Kyte-Doolittle hydropathy plots of polyketide synthase sequences (indicated by thick lines) of A, Q2-87; B, F113; C, Streptomyces griseus; and D, Lycopersicon esculentum compared with CHA0 (indicated by a thin line). Sequence position refers to plant chalcone synthase (CHS) numbering. The hydrophobicity index (positive and negative values indicate hydrophobic and hydrophilic properties, respectively) was calculated for a window of seven residues. Arrows indicate the $\mathrm{C}^{169}$ in plant CHS and the corresponding cysteines in bacterial counterparts. 
Q2-87 (Keel et al. 1996). They were routinely cultivated on King's medium B (King et al. 1954) at $27^{\circ} \mathrm{C}$ and stored at $-80^{\circ} \mathrm{C}$ in $40 \%$ glycerol.

PCR amplification and restriction analysis of phlD.

Two bacterial colonies were suspended in $100 \mu \mathrm{l}$ of lysis buffer (10 mM Tris- $\mathrm{HCl}, \mathrm{pH} 8.3 ; 50 \mathrm{mM} \mathrm{KCl} ; 0.1 \%$ Tween 20 ) and then heat lysed for $10 \mathrm{~min}$ at $99^{\circ} \mathrm{C}$. PCR amplification was performed with forward primer Phl2a (20-mer 5'-GAG GACGTCGAAGACCACCA-3') and reverse primer Phl2b (20-mer 5'-ACCGCAGCATCGTGTATGAG-3'), which were developed from sequences present within phlD (1,047 bp) (Bangera and Thomashow 1999) in P. fluorescens Q2-87 (Raaijmakers et al. 1997). Primers were synthesized by MWG Biotech (Basel, Switzerland). PCR amplification was carried out in $20-\mu$ l reaction mixtures containing $5 \mu$ of heat-lysed bacterial suspension, 1× PCR buffer (Amersham Pharmacia Biotech, Piscataway, NJ, U.S.A.), $100 \mu \mathrm{M}$ (each) dATP, dCTP, dGTP, and dTTP (Amersham Pharmacia), $0.20 \mu \mathrm{M}$ (each) primer, and 1.1 U of Taq DNA polymerase (Amersham Pharmacia). Amplifications were performed with a PTC-100 Programmable Thermal Controller (MJ Research, Watertown, MA, U.S.A.). The initial denaturation $\left(2 \mathrm{~min}\right.$ at $\left.94^{\circ} \mathrm{C}\right)$ was followed by $30 \mathrm{PCR}$ cycles $\left(94^{\circ} \mathrm{C}\right.$ for $40 \mathrm{~s}, 63^{\circ} \mathrm{C}$ for $30 \mathrm{~s}$, and $72^{\circ} \mathrm{C}$ for $30 \mathrm{~s}$ ) and a final extension at $72^{\circ} \mathrm{C}$ for $10 \mathrm{~min}$.

Restriction analysis was performed with $5 \mu$ of amplified product and $10 \mu \mathrm{l}$ of restriction buffer containing $1.5 \mathrm{U}$ of either HaeIII, Sau3A, NdeII, CfoI, or MspI (Boehringer Mannheim, Mannheim, Germany). After a 2-h digestion at $37^{\circ} \mathrm{C}$, restriction fragments were separated by gel electrophoresis $(2.5 \%$ agarose) with standard protocols (Sambrook et al.
1989). A 100-bp ladder (Life Technologies, Gaithersburg, MD, U.S.A.) was used as a molecular size marker. For each Pseudomonas spp. strain, PCR amplification and restriction analysis were performed at least three times. The different patterns obtained with each of the five endonucleases were readily distinguishable from one another and highly reproducible from one experiment to the next.

Calculation of the Jaccard coefficient of pairwise similarity (Jaccard 1908), which was determined by the presence or absence of bands and cluster analysis with the unweighed pair group method with averages (UPGMA) algorithm (Nei and Li 1979), were performed with NTSYS-pc numerical taxonomy and multivariate analysis software (Applied Biostatistics, Setauket, NY, U.S.A.). Only band sizes over 80 bp were evaluated.

\section{Sequencing of phlD.}

phlD sequences were already available for strains CHA0 (GenBank accession no. AF214456), Pf-5 (AF214457), Q8r196 (AF207693), M1-96 (AF207692), and UP61 (AF214108). In the current work, PCR amplicons were purified with the Qiaquick Extraction Kit (Qiagen, Basel, Switzerland) and cloned in pPCR-Script Amp SK(+) cloning vector, according to the manufacturer's recommendations (Stratagene, Zurich, Switzerland). They were directly sequenced with primers M13 and M13rev (Microsynth, Balgach, Switzerland), and phlD sequences were deposited in the EMBL database for strains CHA0 (accession no. AJ278806), Q65c-80 (AJ278807), CM1'A2 (AJ278808), PITR2 (AJ278809), PILH1 (AJ278810), and F113 (AJ278811).

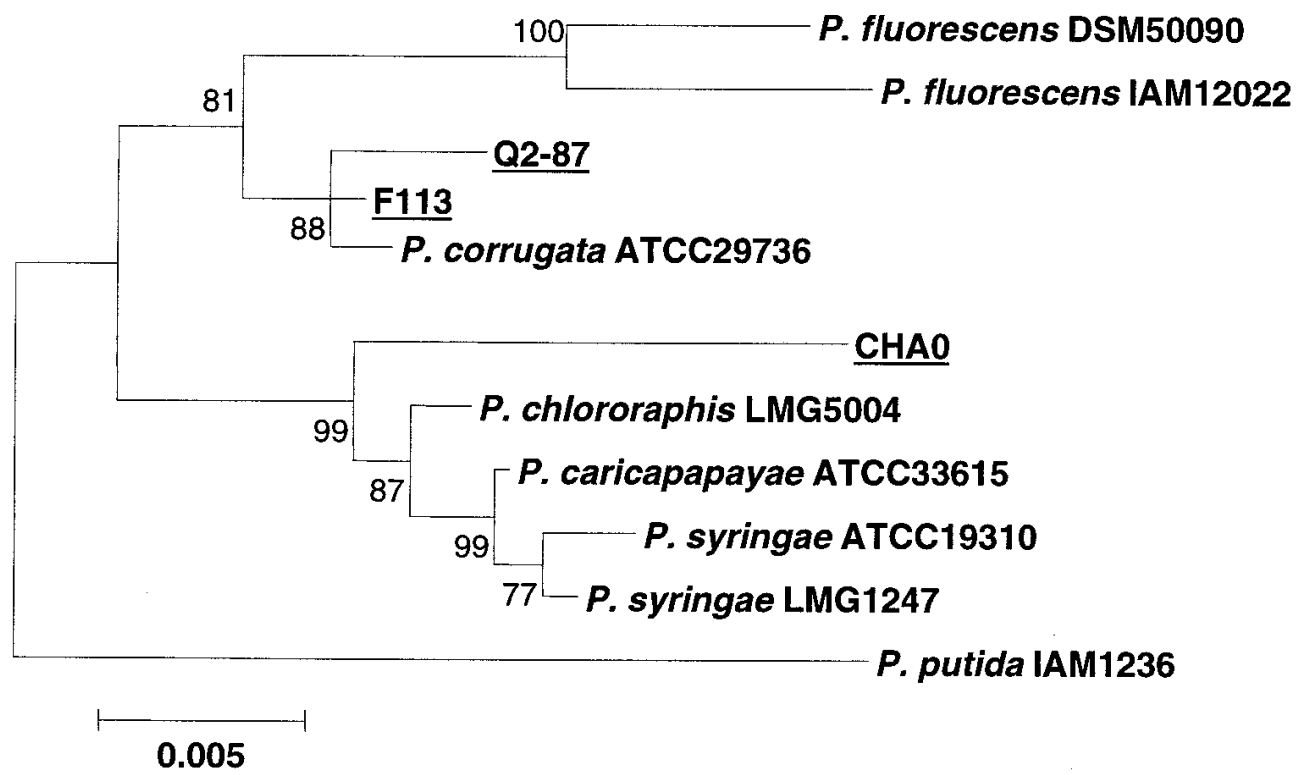

Fig. 6. Phylogenetic relationships between Phl ${ }^{+}$Pseudomonas spp. strains CHA0 (group ARDRA1), Q2-87 (group ARDRA2), F113 (group ARDRA3), and other Pseudomonas spp. based on 16S rDNA sequences. The Neighbor-Joining tree was constructed according to Jukes and Cantor (1969), with Pseudomonas putida IAM1236 as the outgroup (1,000 bootstrap replicates). Scale bar represents the number of nucleotide substitutions per site. Virtual restriction analysis of the $16 \mathrm{~S}$ rDNA sequences of CHA0, Q2-87, and F113 was performed with six enzymes: CfoI, TaqI, AluI, RsaI, HpaII, and HaeIII. Fragment sizes with CfoI: 203, 250, 281, 357, and 439 bp for Q2-87 and F113 and 63, 91, 250, 281, 409, and 436 bp for CHA0; with TaqI: 53, 223, 361, and 893 bp for CHA0 and Q2-87 and 53, 223, 315, 361, and 578 bp for F113; with AluI: 15, 106, 162, 196, 207, 209, 230, and 403 bp for the three strains; with RsaI: 146, 153, 357, and 874 bp for Q2-87 and F113 and 6, 70, 146, 150, 357, and 801 bp for CHA0. With HpaII: 11, 81, 110, 130, 163, 486, and 549 bp for Q2-87 and F113 and 11, 81, 110, 130, 142, 160, 347, and 549 bp for CHA0. With HaeIII: 9, 34, 37, 59, 157, 161, 171, 220, and 682 bp for Q2-87 and F113 and 9, 34, 37, 59, 156, 171, 220, and 844 bp for CHA0. 
Sequencing of $16 \mathrm{~S}$ rRNA genes.

Twenty microliters of heat-lysed cell suspension was used for PCR amplification with a pair of universal primers (FGPF5-255 and FGPS1509'-153) corresponding to Escherichia coli (GenBank accession no. J01859) at positions 5 to 24 and 1,524 to 1,540 (Normand 1995). Additional primers within the sequences were designed to carry out doublestranded coverage of the whole 16S rRNA gene (Normand et al. 1996). PCR was performed in $100 \mu \mathrm{l}$ of reaction volume with the Expand High Fidelity PCR system (Roche Molecular Biochemicals, Mannheim, Germany). PCR amplicons were purified with the Qiaquick Extraction Kit and sequenced by Genome Express (Grenoble, France). Complete 16S rRNA sequences were determined for strains CHA0 (1,531 bp), Q287 (1,528 bp), and F113 (1,527 bp) and are available at the EMBL database at accession nos. AJ278812 (CHA0), AJ278813 (Q2-87), and AJ278814 (F113).
DNA sequence analyses.

Consensus DNA sequences were assembled with the Genetic Computer Group (GCG) fragment assembly system, version 10 (University of Wisconsin, Madison, U.S.A.). Virtual restriction analysis also was carried out with GCG. Multiple sequences were aligned with the CLUSTAL W computer program (Thompson et al. 1994); sites presenting alignment gaps were excluded from analysis (alignments available upon request).

For phlD nucleotide sequences, the maximum-likelihood tree was constructed with the DNA Maximum Likelihood program (DNAML) of the Phylogeny Inference Package (PHYLIP; J. Felsenstein, University of Washington, Seattle, U.S.A.). The strict consensus tree from out of 100 bootstrap replicates (global rearrangements, jumbled five times) was obtained with PHYLIP's CONSENSE program, and tree plotting was performed with TreeExplorer 2.12 (K. Tamura, Penn-
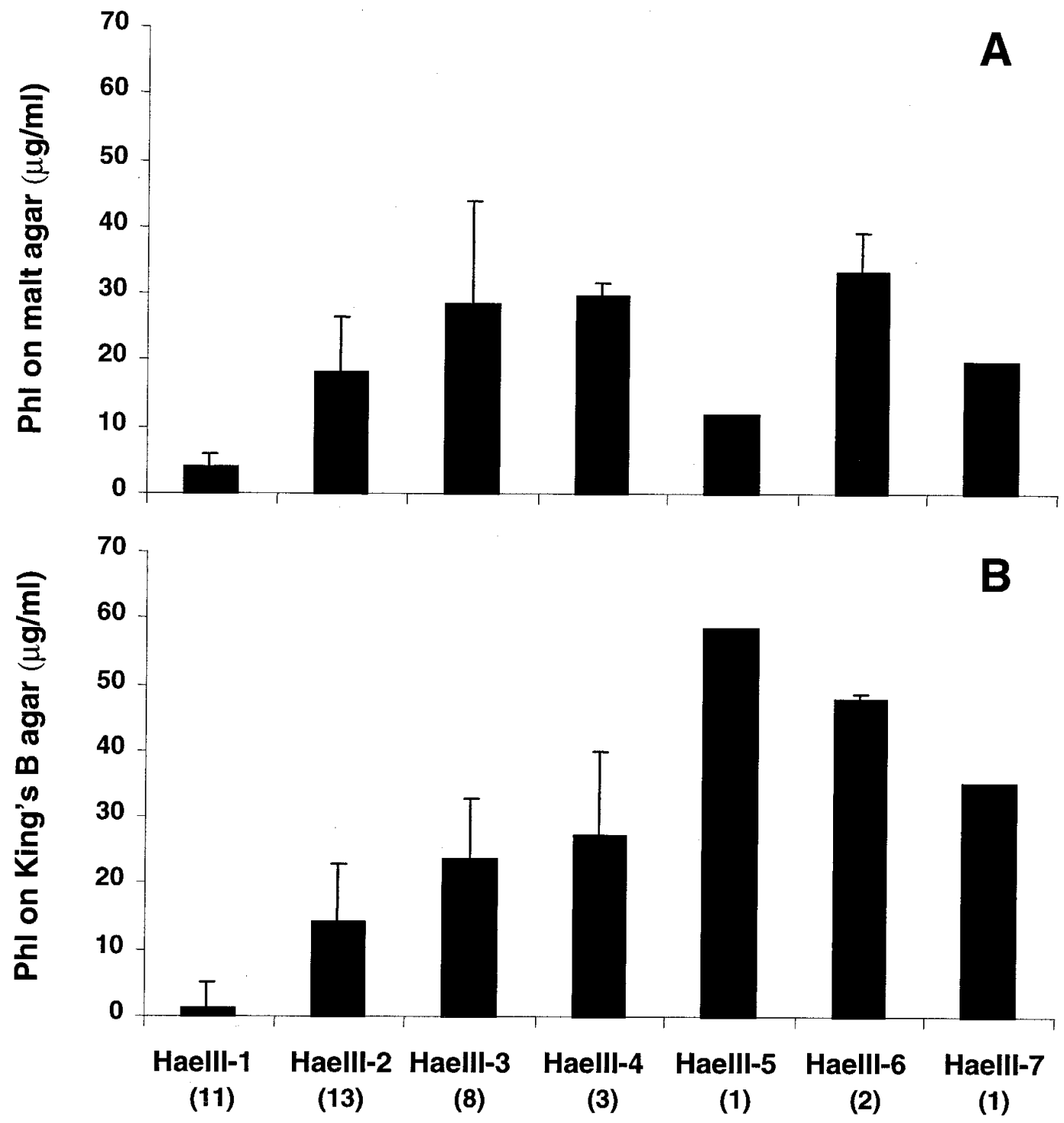

Fig. 7. Phl production on A, malt agar and B, King's B agar, in accordance with phlD polymerase chain reaction-restriction fragment length polymorphism patterns for $39 \mathrm{Phl}^{+}$biocontrol pseudomonads. Means and standard deviations (error bars) were obtained from raw data presented in Keel et al. (1996). The number of bacteria sharing a same restriction pattern is indicated in parentheses. 
sylvania State University, University Park, U.S.A.). Base composition was obtained by the PAML package, and statistical differences between strains in base composition (overall and at each of the three codon positions) were assessed with a Chi-square test at $P<0.05$. The alpha parameter of the gamma distribution and the Ti-Tv ratio were estimated with the model F84 (program BASEML, implemented in the PAML package). The numbers of synonymous (dS) and nonsynonymous substitutions $(\mathrm{dN})$ between each pair of phlD sequences were estimated in accordance with Nei and Gojobori (1986) and implemented in the MEGA program by applying the Jukes-Cantor formula. Statistical comparison between $\mathrm{dN}$ and $\mathrm{dS}$ was performed in MEGA with the use of a Student $t$ test incorporating infinite degrees of freedom. Parsimony analyses were performed with PAUP (implemented in GCG), PHYLIP, or MEGA.

The 16S rRNA sequences were aligned with the most similar sequences of the Ribosomal Database Project database. Only complete sequences that yielded the highest similarity scores were kept for subsequent analysis. The corresponding Pseudomonas spp. strains were P. fluorescens IAM12022 (GenBank accession no. D84013) and DSM 50090 (Z76662), Pseudomonas caricapapayae ATCC33615 (D84010), P. corrugata ATCC29736 (D84012), P. syringae ATCC19310 (D84026) and LMG1247 (Z76669), P. chlororaphis LMG5004 (Z76657), and P. putida IAM1236 (D84020). The sequence alignment was checked manually and corrected. The NJ tree was constructed with MEGA, in accordance with Jukes and Cantor (1969). P. putida IAM1236 was used as the out group. Nodal support of the inferred tree was evaluated by 1,000 bootstrap replicates.

\section{Amino acid sequence analyses.}

Predicted PhlD amino acid sequences were aligned (CLUSTAL W) by taking into account the PhID sequence of strain Q2-87 (accession no. AAB48106). NEIGHBOR, implemented in PLYLIP package, was used to generate a NJ tree, according to the 2-parameter model of Kimura (1980), and statistical support of a given node was evaluated by 1,000 bootstrap replicates. The strict consensus tree was obtained with $\mathrm{CHA0}$ as the outgroup. Parsimony analyses were performed with PAUP (implemented in GCG), PHYLIP, or MEGA. The identity and similarity between PhID sequences were calculated with BLAST 2 program sequences, version 2.0.14 (National Center for Biotechnology Information, Bethesda, MD, U.S.A.), with a BLOSUM62 default matrix gap opening and gap extension penalties of 10 and 1, respectively.

Sequences similar to PhlD were searched in the GenBank and EMBL databases with the BLAST, Fasta3t, and MOTIF programs. The ExPASy molecular tool server was used to scan PROSITE and SWISS-PROT for active site and protein domain similarities. Sequences were aligned with CLUSTAL $\mathrm{W}$ software, and sites presenting alignment gaps were removed from analysis. The NJ tree was generated with 100 bootstrap replicates to assess nodal support with PAUP in the GCG package or 1,000 bootstrap replicates with PHYLIP (Kimura formula). Both methods gave the same tree topology. The 50\%-majority-rule consensus tree was presented unrooted. The identity and similarity between PhlD and other PKSs from plants and gram-positive bacteria were determined as described above.
Kyte-Doolittle (1982) hydropathy plots were determined with the PepPlot program included in the GCG package. The hydrophobicity index was calculated over a window of seven residues.

\section{Phl production.}

Raw data of Phl production (Keel et al. 1996) were used to calculate means and standard deviations (Fig. 7) for strains sharing a same phlD restriction pattern. The raw data did not fit a normal distribution because of skewness and kurtosis of the data, but this could be corrected with a $\log (x+1)$ transformation. When comparing clusters HaeIII-1, HaeIII-2, and HaeIII-3 to HaeIII-7 (Fig. 1) for a given medium, data were $\log (x+1)$ transformed prior to performing analysis of variance and subsequent Tukey "Honestly Significantly Different" tests $(P<0.05)$. Calculations were performed with SYSTAT for Windows, version 7 (SPSS Science, Chicago, IL, U.S.A.).

\section{ACKNOWLEDGMENTS}

We thank C. Wang, A. Natsch (ETH), X. Nesme, and P. Normand (Lyon 1) for useful discussions, and A. Patocchi and L. Gianfranceschi (ETH) for help with molecular methods. This work was supported by the Swiss National Foundation for Scientific Research (project 31-50522).

\section{LITERATURE CITED}

Anzai, Y., Kim, H., Park, J.-Y., Wakabayashi, H., and Oyaizu, H. 2000. Phylogenetic affiliation of the pseudomonads based on $16 \mathrm{~S}$ rRNA sequence. Int. J. Syst. Evol. Microbiol. 50:1563-1589.

Bangera, M. G., and Thomashow, L. S. 1999. Identification and characterization of a gene cluster for synthesis of the polyketide antibiotic 2,4-diacetylphloroglucinol from Pseudomonas fluorescens Q2-87. J. Bacteriol. 191:3155-3163.

Bertolla, F., Frostegård, Å., Brito, B., Nesme, X., and Simonet, P. 1999. During infection of its host, the plant pathogen Ralstonia solanacearum naturally develops a state of competence and exchanges genetic material. Mol. Plant-Microbe Interact. 12:467-472.

Bonsall, R. F., Weller, D. M., and Thomashow, L. S. 1997. Quantification of 2,4-diacetylphloroglucinol produced by fluorescent Pseudomonas spp. in vitro and in the rhizosphere of wheat. Appl. Environ. Microbiol. 63:951-955.

Bossis, E., Lemanceau, P., Latour, X., and Gardan, L. 2000. The taxonomy of Pseudomonas fluorescens and Pseudomonas putida: Current status and need for revision. Agronomie 20:51-63.

Cook, R. J., Thomashow, L. S., Weller, D. M., Fujimoto, D., Mazzola, M., Bangera, M. G., and Kim, D. S. 1995. Molecular mechanisms of defense by rhizobacteria against root disease. Proc. Natl. Acad. Sci. USA 92:4197-4201.

Dowling, D. N., and O'Gara, F. 1994. Metabolites of Pseudomonas involved in the biocontrol of plant disease. Trends Biotechnol. 12:133-144.

Fenton, A. M., Stephens, P. M., Crowley, J., O'Callaghan, M., and O'Gara, F. 1992. Exploitation of gene(s) involved in 2,4diacetylphloroglucinol biosynthesis to confer a new biocontrol capability to a Pseudomonas strain. Appl. Environ. Microbiol. 58:38733878.

Fuchs, J., and Défago, G. 1991. Protection of cucumber plants against black root rot caused by Phomopsis sclerotioides with rhizobacteria. Pages 57-62 in: Plant Growth-Promoting Rhizobacteria-Progress and Prospects (IOBC/WPRS Bull XIV/8). C. Keel, B. Koller, and G. Défago, eds. IOBC/WPRS, Interlaken, Switzerland.

Funa, N., Ohnishi, Y., Fujii, I., Shibuya, M., Ebizuka, Y., and Horinouchi, S. 1999. A new pathway for polyketide synthesis in microorganisms. Nature 400:897-899.

Harrison, L. A., Letendre, L., Kovacevich, P., Pierson, E., and Weller, D. 1993. Purification of an antibiotic effective against Gaeumannomyces graminis var. tritici produced by a biocontrol agent, Pseudomonas aureofaciens. Soil Biol. Biochem. 25:215-221. 
Howell, C. R., and Stipanovic, R. D. 1979. Control of Rhizoctonia solani on cotton seedlings with Pseudomonas fluorescens and with an antibiotic produced by the bacterium. Phytopathology 69:480-482.

Jaccard, P. 1908. Nouvelles recherches sur la distribution florale. Bull. Soc. Vaudoise Sci. Nat. 44:223-270.

Jukes, T. H., and Cantor, C. R. 1969. Evolution of protein molecules. Pages 21-132 in: Mammalian Protein Metabolism. H. N. Munro, ed. Academic Press, New York.

Keel, C., and Défago, G. 1997. Interactions between beneficial soil bacteria and root pathogens: Mechanisms and ecological impact. Pages 27-46 in: Multitrophic Interactions in Terrestrial Systems. A. C. Gange and V. K. Brown, eds. Blackwell Scientific Publishers, London.

Keel, C., Schnider, U., Maurhofer, M., Voisard, C., Laville, J., Burger, U., Wirthner, P., Haas, D., and Défago, G. 1992. Suppression of root diseases by Pseudomonas fluorescens CHA0: Importance of the bacterial secondary metabolite 2,4-diacetylphloroglucinol. Mol. PlantMicrobe Interact. 5:4-13.

Keel, C., Weller, D. M., Natsch, A., Défago, G., Cook, R. J., and Thomashow, L. S. 1996. Conservation of the 2,4-diacetylphloroglucinol biosynthesis locus among fluorescent Pseudomonas strains from diverse geographic locations. Appl. Environ. Microbiol. 62:552563.

Kimura, M. 1980. A simple method for estimating evolutionary rate of base substitutions through comparative studies of nucleotide sequences. J. Mol. Evol. 16:111-120.

Kimura, M. 1983. The Neutral Theory of Molecular Evolution. Cambridge University Press, Cambridge, MA, U.S.A.

King, E. O., Ward, M. K., and Raney, D. E. 1954. Two simple media for the demonstration of pyocyanin and fluorescein. J. Lab. Clin. Med. 44:301-307.

Kyte, J., and Doolittle, R. F. 1982. A simple method for displaying the hydrophobic character of a protein. J. Mol. Biol. 157:105-132.

Lanz, T., Tropf, S., Marner, F. J., Schröder, J., and Schröder, G. 1991. The role of cysteines in polyketide synthases: Site-directed mutagenesis of resveratrol and chalcone synthases, two key enzymes in different plant-specific pathways. J. Biol. Chem. 266:9971-9976.

Levy, E., Gough, F. J., Berlin, K. D., Guiana, P. W., and Smith, J. T. 1992. Inhibition of Septoria tritici and other phytopathogenic fungi and bacteria by Pseudomonas fluorescens and its antibiotics. Plant Pathol. 41:335-341.

Martin, C. R. 1993. Structure, function, and regulation of the chalcone synthase. Int. Rev. Cytol. 147:233-284.

McSpadden Gardener, B. B., Schroeder, K. L., Kalloger, S. E., Raaijmakers, J. M., Thomashow, L. S., and Weller, D. M. 2000. Genotypic and phenotypic diversity of phlD-containing Pseudomonas strains isolated from the rhizosphere of wheat. Appl. Environ. Microbiol. 66:1939-1946.

Miyata, T., and Yasugana, T. 1980. Molecular evolution of mRNA: A method for estimating evolutionary rates of synonymous and amino acid substitutions from homologous nucleotide sequences and its application. J. Mol. Evol. 16:23-36.

Moore, E. R. B., Mau, M., Arnscheidt, A., Böttger, E. C., Hutson, R. A., Collins, M. D., Van de Peer, Y., De Wachter, R., and Timmis, K. N. 1996. The determination and comparison of the 16S rRNA gene sequences of species of the genus Pseudomonas (sensu stricto) and estimation of the natural intrageneric relationships. Syst. Appl. Microbiol. 19:478-492

Nei, M., and Li, W. H. 1979. Mathematical model for studying genetic variation in terms of restriction endonucleases. Proc. Natl. Acad. Sci. USA 76:5269-5273.

Nei, M., and Gojobori, T. 1986. Simple methods for estimating the numbers of synonymous and nonsynonymous nucleotide substitutions. Mol. Biol. Evol. 3:418-426.

Nielsen, R., and Yang, Z. 1998. Likelihood models for detecting positively selected amino acid sites and applications to the HIV-1 envelope gene. Genetics 148:929-936.

Normand, P. 1995. Utilisation des séquences 16S pour le positionnement phylétique d'un organisme inconnu. Oceanis 21:31-56.

Normand, P., Orso, S., Cournoyer, B., Jeannin, P., Chapelon, C., Dawson, J., Evtushenko, L., and Misra, A. K. 1996. Molecular phylogeny of the genus Frankia and related genera and emendation of the family Frankiaceae. Int. J. Syst. Bacteriol. 46:1-9.

Palleroni, N. J. 1992. Introduction to the family Pseudomonadaceae
Pages 3071-3085 in: The Prokaryotes, Vol. 3. A. Ballows, H. G. Trüper, M. Dworkin, W. Harder, and K. H. Schleifer, eds. SpringerVerlag, New York.

Picard, C., Di Cello, F., Ventura, M., Fani R., and Guckert, A. 2000. Frequency and biodiversity of 2,4-diacetylphloroglucinol-producing bacteria isolated from the maize rhizosphere at different stages of plant growth. Appl. Environ. Microbiol. 66:948-955.

Pierson, E. A., and Weller, D. M. 1994. Use of mixtures of fluorescent pseudomonads to suppress take-all and improve the growth of wheat. Phytopathology 84:940-947.

Raaijmakers, J. M., Weller, D. M., and Thomashow, L. S. 1997. Frequency of antibiotic-producing Pseudomonas spp. in natural environments. Appl. Environ. Microbiol. 63:881-887.

Raaijmakers, J. M., Bonsall, R. F., and Weller, D. M. 1999. Effect of population density of Pseudomonas fluorescens on production of 2,4diacetylphloroglucinol in the rhizosphere of wheat. Phytopathology 89:470-475.

Sambrook, J., Fritsch, E. F., and Maniatis, T., 1989. Molecular Cloning: A Laboratory Manual, 2nd ed. Cold Spring Harbor Laboratory, Cold Spring Harbor, NY, U.S.A.

Schröder, J., and Schröder, G. 1990. Stilbene and chalcone synthases: Related enzymes with key functions in plant-specific pathways. Z Naturforsch. 45c: $1-8$

Shanahan, P., O'Sullivan, D. J., Simpson P., Glennon, J. D, and O'Gara, F. 1992. Isolation of 2,4-diacetylphloroglucinol from a fluorescent pseudomonad and investigation of physiological parameters influencing its production. Appl. Environ. Microbiol. 58:353-358.

Sharifi-Tehrani, A., Zala, M., Natsch, A., Moënne-Loccoz, Y., and Défago, G. 1998. Biocontrol of soilborne fungal plant diseases by 2,4 diacetylphloroglucinol-producing fluorescent pseudomonads with different restriction profiles of amplified 16S rDNA. Eur. J. Plant Pathol. 104:631-643.

Sorokin, A., Azevedo, V., Zumstein, E., Galleron, N., Ehrlich, S. D., and Serror, P. 1996. Sequence analysis of the Bacillus subtilis chromosome region between the serA and $\mathrm{kdg}$ loci cloned in yeast artificial chromosome. Microbiology 142:2005-2016.

Stackebrandt, E., and Goebel, B. M. 1994. Taxonomic note: A place for DNA-DNA reassociation and rRNA sequence analysis in the present species definition in bacteriology, Int. J. Syst. Bacteriol. 44:846-849.

Stutz, E. W. 1985. Krankheitsunterdrueckende Boeden in der Westschweiz. Ph.D. Diss. Swiss Federal Institute of Technology, Zurich, Switzerland.

Stutz, E. W., Défago, G., and Kern, H. 1986. Naturally occurring fluorescent pseudomonads involved in suppression of black root rot of tobacco. Phytopathology 76:181-185.

Swofford, D. L., Olsen, G. J., Waddell, P. J., and Hillis, D. M. 1996. Phylogenetic inference. Pages 407-514 in: Molecular Systematics, 2nd ed. D. M. Hillis, C. Moritz, and B. K. Mable, eds. Sinauer Associates, Sunderland, MA, U.S.A.

Thomashow, L. S., and Weller, D. M. 1996. Current concepts in the use of introduced bacteria for biological disease control: mechanisms and antifungal metabolites. Pages 187-235 in: Plant-Microbe Interactions, Vol. 1. G. Stacey and N. Keen, eds. Chapman \& Hall, New York.

Thompson, J. D., Higgins, D. G., and Gibson, T. J. 1994. CLUSTAL W: Improving the sensitivity of progressive multiple sequence alignment through sequence weighting, positions-specific gap penalties and weight matrix choice. Nucleic Acids Res. 22:4673-4680.

Tropf, S., Kärcher, B., Schröder, G., and Schröder, J. 1995. Reaction mechanisms of homodimeric plant polyketide synthases (stilbene and chalcone synthase). J. Biol. Chem. 270:7922-7928.

Troussieux, S. 2000. Etude du Rôle de la Transformation Bactérienne Naturelle en tant que Mécanisme de Transfert d'ADN aux Microorganismes du Sol. Ph.D. Diss. Université Lyon 1, Villeurbanne, France.

Troxler, J., Berling, C. H., Moënne-Loccoz, Y., Keel, C., and Défago, G. 1997. Interactions between the biocontrol agent Pseudomonas fluorescens $\mathrm{CHA} 0$ and Thielaviopsis basicola in tobacco roots observed by immunofluorescence microscopy. Plant Pathol. 46:62-71.

Ueda, K., Kim, K. M., Beppu, T., and Horinouchi, S. 1995. Overexpression of a gene cluster encoding a chalcone synthase-like protein confers red-brown pigment production in Streptomyces griseus. J. Antibiot. 48:638-646

Vincent, M. N., Harrison, L. A., Brackin, J. M., Kovacevich, P. A., 
Mukerji, P., Weller, D. M., and Pierson, E. A. 1991. Genetic analysis of the antifungal activity of a soilborne Pseudomonas aureofaciens strain. Appl. Environ. Microbiol. 57:2928-2934.

Yang, Z. 1998. Likelihood ratio tests for detecting positive selection and application to primate lysozyme evolution. Mol. Biol. Evol. 15:568-
573.

Zuurbier, K. W. M., Leser, J., Berger, T., Hofte, A. J. P., Schröder, G., Verpoorte, R., and Schröder, J. 1998. 4-Hydroxy-2-pyrone formation by chalcone and stilbene synthase with nonphysiological substrates. Phytochemistry 49:1945-1951. 